\title{
IMPLEMENTASI PIJAT REFLEKSI KAKI TERHADAP PENURUNAN TEKANAN DARAH PADA KLIEN DENGAN HIPERTENSI TIDAK TERKONTROL
}

\section{Implementation of Foot Reflexology Massage to Decrease Blood Pressure in Clients with Uncontrolled Hypertension}

\author{
Muhammad Fandizal $^{1 *}$, Yuli Astuti ${ }^{2}$, Dhien Novita Sani ${ }^{3}$ \\ 1,2,3 Universitas Bhakti Kencana Jakarta, Indonesia 13860 \\ *Korespondensi Penulis : muhammad.fandizal@bku.ac.id
}

\begin{abstract}
Abstrak
Klien yang mengalami tekanan darah meningkat lebih dari $140 / 90 \mathrm{mmHg}$ pada dua hari berturutturut dalam keadaan istirahat. Angka kejadian hipertesi di dunia sebanyak 1,13 milyar orang, $34,1 \%$ di Indonesia, dan 34,95\% di DKI Jakarta. Untuk menurunkan angka komplikasi dari hipertensi dapat dilakukan dengan terapi non farmakologis yaitu dengan terapi komplementer pijat refleksi kaki.

Tujuan penelitian ini untuk menganalisis pengaruh pijat refleksi kaki terhadap penurunan tekanan darah pada klien dengan hipertensi tidak terkontrol di kelurahan Pondok Ranggon pada tahun 2019. Penelitian ini merupakan penelitian Pre Eksperimen dengan pendekatan asuhan keperawatan. Bentuk desain penelitian yaitu One Group Pretest-Postest. Sampel dalam penelitian ini sebanyak 6 orang klien dengan menggunakan teknik Non Probability Sampling yaitu purposive sampling. variabel dependen pada penelitian ini yaitu Tekanan darah yang diukur dengan alat pengukur tensi meter, pengukuran dilakukan sebelum intervensi dan setelah implementasi keperawatan. Variable independen yaitu implementasi pijat refleksi kaki dengan standar operasional prosedur (SPO) keperawatan selama 10-15 menit. Teknik analisis dengan uji T Paired dengan program komputer. Terdapat perbedaan sebelum dan sesudah dilakukan intervesi pijat refleksi kaki untuk menurunkan tekanan darah pada klien dengan penyakit hipertensi $(\rho 0,006<0,05)$. Mean bernilai postif $(8,66667)$ terjadi kecenderungan penurunan tekanan darah sesudah pijat refleksi kaki dengan ratarata penurunan 8,7 .

Penurunan tekanan darah dapat terjadi karena pijat refleksi kaki dapat mempelancar aliran darah sehingga ketegangan otot dapat menurun serta kadar norefineprin juga ikut menurun, selain itu homon Cortisol yang memicu kecemasan dan stress juga dapat turun sehingga tekanan darah juga turun.

Tekanan darah tinggi pada klien dengan penyakit hipertensi dapat diturunkan dengan intervensi non-farmakologis yaitu dengan pijat refleksi kaki selama 6 hari.
\end{abstract}

Kata kunci : Hipertensi, Penurunan Tekanan darah, Pijat Refleksi kaki

\begin{abstract}
Increased blood pressure of more than $140 / 90 \mathrm{mmHg}$ on two consecutive days in the state of rest. The incidence of hypertension in the world is 1.13 billion people, $34.1 \%$ in Indonesia, and $34.95 \%$ in DKI Jakarta. To reduce the number of complications from hypertension can be done with nonpharmacological therapy, namely complementary therapy reflexology foot massage. The aim of this study was to analyze the effect of foot reflexology massage on the reduction in blood pressure in clients with uncontrolled hypertension in the kelurahan Pondok Ranggon in 2019.

This research is a Pre Experiment research with nursing care. The research design is One Group Pretest-Posttest. The sample in this study amounted to 6 clients using the Non Probability Sampling technique that is Purposive Sampling. The dependent variable in this study is blood pressure as measured by a tensi meter, measurements taken before intervention and after implementation of nursing. The independent variable is the implementation of foot reflexology with nursing standard operational procedures (SOP) for 10-15 minutes. Analysis technique with the T test Paired with a computer program
\end{abstract}

Submitted : 17 Mei 2020, Accepted $\quad$ : 2 Juni 2020

Website : jurnal.stikespamenang.ac.di | Email : jurnal.pamenang@gmail.com 
There were differences before and after the foot reflexology massage intervention to reduce blood pressure in clients with hypertension $(\rho 0.006<0.05)$. The mean value is positive (8.66667). There is a tendency for a decrease in blood pressure after a reflexology foot massage with an average decrease of 8.7.

Decreased blood pressure can occur because reflexes in the legs can smoothen the blood flow so that muscle tension can decrease and the levels of norepinephrine also decrease, in addition, hormone cortisol which triggers anxiety and stress can also fall so that blood pressure also drops. High blood pressure in clients with hypertension can be reduced by non-pharmacological interventions, namely foot reflexology massage for 6 days.

Keywords : Decreased Blood Pressure, Foot Reflexology Massage, Hypertension

\section{Pendahuluan}

Peningkatan tekanan darah pada klien dengan penyakit hipertensi menunjukkan hasil diatas 140/90 $\mathrm{mmHg}$ atau lebih dalam keadaan istirahat pada dua hari berturut-turut (Medika, 2017; WHO, 2020). Sebanyak 1,13 milyar orang di dunia menderita penyakit hipertensi. Angka kejadian hipertensi di Indonesia sebesar 34,1\% (Kesehatan, 2018). Angka kejadian hipertensi di DKI Jakarta sebesar 34,95\% (Dinkes, 2017). Berdasarkan hasil wawancara dengan kepala puskesmas kelurahan Pondok Ranggon, data terakhir terdapat 201 orang mengalami hipertensi pada tahun 2017. 1 dari 5 orang perempuan dan 1 dari 4 orang laki-laki menderita penyakit hipertensi, serta 1 dari 5 orang dengan hipertensi tidak terkontrol. Penyakit hipertensi yang tidak dikontrol akan meningkatkan resiko penyakit lain yaitu penyakit jantung, stroke, gagal ginjal, kebutaan, dan lainnya (WHO, 2020). Untuk menghindari komplikasi dari penyakit hipertensi, perawat mempunyai peran penting.

Mencegah terjadinya komplikasi dari penyakit hipertensi dapat dilakukan secara komprehensif baik secara promotif, preventif, kuratif dan rehabilitatif. Peran kuratif yang dapat dilakukan perawat secara non farmakologi yaitu dengan cara relaksasi dengan tindakan pijat kaki (Febriyanto et al., 2019; Fandizal, Astuti and Sani, 2020). Pemilihan tindakan non farmakologi menjadi utama karena tindakan menggunakan terapi farmakologi mempunyai efek samping yang tidak bagus untuk kedepannya yang akan dialami klien (Rezky, Hasneli and Hasanah, 2015).

Telapak kaki merupakan ujung-ujung syaraf yang dapat di stimulasi dengan pijatan lembut dengan tangan. Pijat refleksi dapat mempelancar aliran darah, menurunkan kadar norefineprin, menurunkan kadar hormone cortisol, menurunkan ketegangan otot, sehingga dapat menurunkan stress yang secara tidak lansung menurunkan tekanan darah (Churniawati, Martini and Wahyuni, 2015; Arianto, Prastiwi and Sutriningsih, 2018; Umamah and Paraswati, 2019).

Hasil penelitian menunjukan terdapat pengaruh pijat refleksi kaki dengan penurunan tekanan darah dengan $\rho$ 0,000; 0,000 (Hartutik and Suratih, 2017; Ratnawati and Aswad, 2019). Hasil penelitian lainnya yang lebih merinci penurunan tekanan darah systole dan diastole dengan implementasi pijat refleksi kaki $\rho$ 0,000 \& 0,004; 0,032 \& 0,024; 0,000 \& 0,001 (Udani, 2016; Amin and Priyono, 2018; Yanti, Rahayuningrum and Arman, 2019).

Tujuan penelitian ini untuk menganalisis pengaruh pijat refleksi kaki terhadap penurunan tekanan darah pada klien dengan hipertensi tidak terkontrol di kelurahan Pondok Ranggon pada tahun 2019.

\section{Metode}

Penelitian ini dilakukan pada klien komunitas kelurahan Pondok Ranggon, Jakarta Timur dengan penyakit hipertensi pada tahun 2019, penelitian ini merupakan penelitian Pre Eksperimen dengan pendekatan asuhan keperawatan. Data tekanan darah dikumpulkan sebelum intervesi dan setelah implementasi keperawatan. Bentuk desain penelitian yang digunakan yaitu One Group Pretest-Postest. Variabel dependen pada penelitian ini Tekanan darah yaitu dorongan darah yang keluar dari jantung yang diukur menggunakan alat pengukur tensi meter dengan skala interval, pengukuran dilakukan sebelum dan setelah intervensi sehingga didapatkan hasil tekanan sistolik dan diastolik selama 6 hari (Dharma, 2011; Sastroasmoro and Ismael, 2014), kemudian hasil pengukuran tekanan darah di konversikan dengan rumus ke nilai Mean Arterial Pressure 
(MAP). Variable independen yaitu implementasi pijat refleksi kaki dengan standar operasional prosedur (SPO) keperawatan selama 10-15 menit pada titik refleksi yang terdapat pada jempol kaki yaitu titik $1-5$ dan semua jari-jari kaki yaitu titik 2 . Titik refleksi selanjutnya yaitu titik 33 jantung, titik 18 hati, dan titik 22 ginjal yang terdapat dibagian bawah telapak kaki mulai dari ujung kaki sampai tumit.

Sampel dalam penelitian ini sebanyak 6 orang klien dengan menggunakan teknik Non Probability Sampling yaitu Purposive Sampling. Kriteria inklusi pada penelitian ini yaitu klien hipertensi tidak terkontrol, usia 50 - 55 tahun, tidak dalam terapi obat, dan kooperatif dalam melakukan intervensi selama 6 hari. Kriteria eksklusi yaitu klien yang minum obat dan tidak mengikuti terapi pijat refleksi selama 6 hari.

Teknik analisis dengan uji $T$ Paired yaitu melihat pengaruh pijat refleksi kaki antara sebelum intervesi dan setelah implementasi dengan signifkansi $95 \%$ pada program program komputer (Sugiyono, 2007; Swarjana, 2015).

\section{Hasil}

Implementasi pijat refleksi kaki terhadap penurunan tekanan darah pada klien hipertensi pada 6 klien didapatkan penurunan tekanan darah pada pada klien hipertensi (mean arterial pressure $=\mathrm{MAP}$ ). Hasil pemeriksaan tekanan darah klien sebelum intervensi dapat terlihat [ada table 1 yaitu antara 150/80 (103) - 160/100 (120) mmHg, setelah diberikan intervesi pijat refleksi kaki selama $10-15$ menit dalam waktu 6 hari, didapatkan hasil implementasi antara 140/80 (107) - 140/90 (100) $\mathrm{mmHg}$.

Tabel 1. Perbandingan Tekanan darah (MAP) sebelum dan sesudah Intervensi

\begin{tabular}{lll}
\hline \multirow{2}{*}{ Responden } & \multicolumn{1}{l}{ Tekanan Darah (MAP) } \\
\cline { 2 - 3 } & Sebelum Intervensi & Setelah Implementasi \\
\hline 1 & $150 / 90(110) \mathrm{mmHg}$ & $140 / 80(100) \mathrm{mmHg}$ \\
2 & $150 / 80(103) \mathrm{mmHg}$ & $140 / 80(100) \mathrm{mmHg}$ \\
3 & $160 / 100(120) \mathrm{mmHg}$ & $140 / 90(107) \mathrm{mmHg}$ \\
4 & $160 / 90(113) \mathrm{mmHg}$ & $140 / 80(100) \mathrm{mmHg}$ \\
5 & $150 / 100(117) \mathrm{mmHg}$ & $140 / 90(107) \mathrm{mmHg}$ \\
6 & $150 / 90(110) \mathrm{mmHg}$ & $140 / 90(107) \mathrm{mmHg}$ \\
\hline
\end{tabular}

Analisa statistic uji $T$ paired didapatkan sebagai berikut:

Tabel 2. Paired Samples Test

\begin{tabular}{lll}
\hline & Mean & Sig. (2-tailed) \\
Pair1 MAP_1 \& MAP_2 & 8.66667 & 0.006 \\
\hline
\end{tabular}

Tabel 2 menggambarkan terdapat perbedaan sebelum dan sesudah dilakukan intervesi pijat refleksi kaki untuk menurunkan tekanan darah pada klien dengan penyakit hipertensi ( $\rho$ $0,006<0,05)$. Mean bernilai postif $(8,66667)$ terjadi kecenderungan penurunan tekanan darah sesudah pijat refleksi kaki dengan ratarata penurunan 8,7 .

\section{Pembahasan}

Asuhan keperawatan pada klien dengan hipertensi di komunitas dilakukan mulai pengkajian, menentukan diagnose keperawatan, intervensi, implementasi dan evaluasi. Intervensi pada klien dengan penyakit hipertensi di keperawatan komunitas dapat dilakukan dengan intervensi komplementer pijat refleksi pada kaki. Implementasi terapi pijat refleksi kaki pada 6 klien dilakukan selama 6 kali intervensi.

Setelah membandingkan hasil intervensi hari pertama sampai hari ke enam, didapatkan hasil terdapat perbedaan tekanan darah sebelum dengan sesudah intervensi dengan $\rho$ $0,006<0,05$. Hasil penelitian ini didukung hasil penelitian lainnya dengan $\rho \quad 0,000$; 0,001; 0,000 < 0,05 (Amalia, 2018; Arianto, Prastiwi and Sutriningsih, 2018; Umamah and Paraswati, 2019). Hasil penelitian ini berbeda dari peneliti lainnya $\rho 0,263>0,05$ perbedaan hasil ini dapat disebabkan karena hipertensi primer tekanan darah akan konstan dalam waktu yang lama sehingga diperlukan usaha yang lebih untuk mengontrolnya (Rezky, Hasneli and Hasanah, 2015).

Pijat refleksi kaki yang dilakukan selama 10-15 menit sehari menggunakan baby oil. Titik refleksi pijat kaki untuk hipertensi terdapat pada jempol kaki yaitu titik $1-5$ dan semua jari-jari kaki yaitu titik 2. Titik refleksi selanjutnya yaitu titik 33 jantung, titik 18 hati, dan titik 22 ginjal yang terdapat dibagian bawah telapak kaki mulai dari ujung kaki sampai tumit. Tindakan ini bermanfaat untuk meningkatkan metabolisme, sirkulasi darah, meningkatkan keseimbangan hormon, menghilangkan kelelahan, membuang toksin, dan lain-lain.

Klien mengatakan badan lebih ringan dan sakit kepala berkurang setelah dilakukan refleksi kaki hal ini diakibatkan menurunnya tekanan darah (Febriyanto et al., 2019). Selain itu pijat refleksi kaki juga dapat menurunkan kadar cortisol yang memicu hormon stress, 
kejadian depresi dan kecemasan juga menurun, sehingga fungsi tubuh semakin membaik karena tekanan darah terus turun mendekati normal (Rezky, Hasneli and Hasanah, 2015). Pijat refleksi juga dapat membersihkan ada nya blok chi di sepanjang saluran dalam tubuh menurut meridian Traditional Chiness Medicine (Amalia, 2018).

Vasodepresor atau antihipertensi dihasilkan oleh ginjal yaitu prostaglandin dan nitrat oksida yang dapat melawan efek vasopresor angiotensin sehingga pembuluh darah mengalami pelebaran dan relaksasi. Pengaturan tekanan darah jangka pendek dilakukan melalu syaraf selama beberapa detik sampai menit dengan mengirim sinyal ke medulla oblongata sehingga dapat menyebabkan dilatasi arteriol, dilatasi vena besar, perlambatan jantung, dan pengurangan kekuatan kontraksi otot jantung. Pengaturan jangka panjang dilakukan melalui ginjal dengan mengatur kosentari garam dan air dalam tubuh. Apabila tekanan darah meningkat, maka konsentrasi garam dan air akan diturunkan dengan pelepasan melalui urin, jika tekanan darah turun dibawah normal, maka air dan garam akan di absorbs kembali oleh ginjal (Hall and Hall, 2010; Andi, Afriwardi and Iryani, 2016; Barrett et al., 2019).

Hasil mean yang bernilai postif 8,7 berarti terjadi kecenderungan penurunan tekanan darah sesudah pijat refleksi kaki dengan rata-rata penurunan 8,7. Penurunan 8,7 dapat sebagai acuan bahwa intervensi ini dapat menjadi pilihan utama diantara intervensi non farmakologi lainnya. Intervensi non farmakologis lainnya yang dapat dilakukan yaitu menurunkan berat badan, pembatasan alkohol, pembatasan natrium, pembatasan rokok, melakukan relaksasi, dan latihan fisik yang harus dilakukan dalam penurunan tekanan darah pada klien dengan hipertensi (Smeltzer et al., 2012; Umamah and Paraswati, 2019).

\section{Kesimpulan}

Asuhan keperawatan pada klien dengan penyakit hipertensi, tekanan darah klien dapat diturunkan dengan intervensi nonfarmakologis yaitu dengan pijat refleksi kaki.

\section{Saran}

Pijat refleksi kaki dapat digunakan sebagai pengontrol kestabilan tekanan darah oleh karena itu perlu dilakukan pelatihan kepada keluarga untuk melakukan pijat refleksi terutama dibagian kaki.

\section{Ucapan Terimakasih}

Terimakasih kepada bapak Ismail selaku ketua RT 005 dan kader yang telah menjembatani pelaksanaan penelitian ini kepada warga sehingga diterima dengan baik.

\section{Daftar Pustaka}

Amalia, R. (2018) Efektifitas Pijat Refleksi Kaki Terhadap Penurunan Tekanan Darah Lansia Hipertensi Di PSTW Budi Luhur Yogyakarta. doi: 10.31227/osf.io/59z3w.

Amin, M. and Priyono, S. (2018) 'Perubahan Tekanan Darah pada Lansia Hipertensi Menggunakan Alat Pijat Refleksi Kaki Elektrik di PSTW Jember', Jurnal Kesehatan dr. Soebandi, 6(1), pp. 489-492. Available at: http://journal.stikesdrsoebandi.ac.id/index.ph $\mathrm{p} / \mathrm{jkds} /$ article/download/107/98.

Andi, A., Afriwardi, A. and Iryani, D. (2016) 'Gambaran Perubahan Tekanan Darah Pasca Olahraga Futsal pada Mahasiswa Fakultas Kedokteran Universitas Andalas', Jurnal Kesehatan Andalas, 5(2), pp. 319-324. Available at: http://jurnal.fk.unand.ac.id/index.php/jka/arti cle/view/515.

Arianto, A., Prastiwi, S. and Sutriningsih, A. (2018) 'Pengaruh Terapi Pijat Refleksi Telapak Kaki Terhadap Perubahan Tekanan Darah Pada Penderita Hipertensi', Nursing News, 3(1), pp. 584-594. Available at: https://publikasi.unitri.ac.id/index.php/fikes/a rticle/viewFile/830/644

Barrett, K. E. et al. (2019) Ganong's Review of Medical Physiology. 26th edn. New York: McGraw Hill.

Churniawati, L., Martini, S. and Wahyuni, C. U. (2015) 'Prehipertensi pada Obesitas Abdominal', Kesmas: National Public Health Journal, 9(4), pp. 293-299. doi: http://dx.doi.org/10.21109/kesmas.v9i4.732.

Dharma, K. K. (2011) Metodologi penelitian keperawatan: Panduan melaksanakan dan menerapkan hasil penelitian. Jakarta: TIM.

Dinkes (2017) Profil Kesehatan Provinsi DKI Jakarta. Jakarta. Available at: https://dinkes.jakarta.go.id/wpcontent/uploads/2019/12/PROFILKESEHATAN-DKI-JAKARTA-TAHUN2017.pdf (Accessed: 10 May 2020).

Fandizal, M., Astuti, Y. and Sani, D. N. (2020) 'Implementation Of Solawatan Music On Pain Decrease In Clients With Hypertension', 
Journal Prima Health Science, 1(2), pp. 53$56 . \quad$ Available at: https://scholar.google.co.id/citations?user=bv szhVwAAAAJ\&hl=id.

Febriyanto, K. et al. (2019) 'Pengabdian Masyarakat Melalui Pemanfaatan Jalan Terapi pada Lansia di Desa Sumber Sari, Kutai Kartanegara', Sarwahita: Jurnal Pengabdian Kepada Masyarakat, 16(2), pp. 167-174. doi: https://doi.org/10.21009/sarwahita.162.08.

Hall, J. and Hall, J. (2010) Guyton and Hall Textbook of Medical Physiology. 12th edn. Philadelphia: Saunders.

Hartutik, S. and Suratih, K. (2017) 'Pengaruh Terapi Pijat Refleksi Kaki Terhadap Tekanan Darah Pada Penderita Hipertensi Primer', GASTER, 15(2), pp. 132-146. Available at: https://publikasi.unitri.ac.id/index.php/fikes/a rticle/view/830.

Kesehatan, K. (2018) RISKESDAS, Badan Penelitian dan Pengembangan Kesehatan. Available at: https://www.persi.or.id/images/2017/litbang/r iskesdas_launching.pdf (Accessed: 10 May 2020).

Medika, T. B. (2017) 'Berdamai dengan hipertensi', in Sari, Y. N. I. (ed.) Monograf. Jakarta: Bumi Medika, pp. 127-129.

Ratnawati, R. and Aswad, A. (2019) 'Efektivitas Terapi Pijat Refleksi dan Terapi Benson terhadap Penurunan Tekanan Darah pada Penderita Hipertensi', Jambura Health and Sport Journal, Volume 1(1), pp. 33-40. Available at: http://ejurnal.ung.ac.id/index.php/jhsj/article/ view/2052.

Rezky, R. A., Hasneli, Y. and Hasanah, O. (2015) 'Pengaruh Terapi Pijat Refleksi Kaki
Terhadap Tekanan Darah Pada Penderita Hipertensi Primer', Jurnal Online Mahasiswa, 2(2), pp. 1-20. Available at: https://www.neliti.com/publications/186872/p engaruh-terapi-pijat-refleksi-kaki-terhadaptekanan-darah-pada-penderita-hipert\#cite.

Sastroasmoro, S. and Ismael, S. (2014) Dasardasar metodologi penelitian klinis. Edisi Ke5. Jakarta: Sagung.

Smeltzer, S. C. et al. (2012) Brunner \& Suddarth's Textbook of Medical Surgical Nursing. 12th edn. Philadelphia: Lippincott Williams \& Wilkins.

Sugiyono (2007) Statistika Untuk Penelitian. Bandung: Alfabeta.

Swarjana, I. K. (2015) Metodologi Penelitian Kesehatan. Revisi. Yogyakarta: ANDI.

Udani, G. (2016) 'Pengaruh Massase pada Penderita Hipertensi di UPTD Panti Tresna Werdha Lampung Selatan', Jurnal Kesehatan, 7(3), p. 503. doi: 10.26630/jk.v7i3.236.

Umamah, F. and Paraswati, S. (2019) 'Pengaruh Terapi Pijat Refleksi Kaki Dengan Metode Manual Terhadap Tekanan Darah Pada Penderita Hipertensi Di Wilayah Karangrejo Timur Wonokromo Surabaya', Jurnal Ilmu Kesehatan, 7(2), p. $295 . \quad$ doi: $10.32831 /$ jik.v7i2.204.

WHO (2020) Hypertension, WHO. Available at: https://www.who.int/healthtopics/hypertension/\#tab=tab_1.

Yanti, E., Rahayuningrum, D. C. and Arman, E. (2019) 'Efektifitas Massase Punggung dan Kaki terhadap Tekanan Darah pada Penderita Hipertensi', Jurnal Kesehatan Medika Saintika, 10(1), pp. 18-31. doi: 10.30633/JKMS.V10I1.305. 